\title{
Sweetpotato weevil pheromones and their precursors: Dose-response and structure-activity relationship in Cylas formicarius Fabr., Cylas brunneus Olivier and Cylas puncticollis Boheman
}

\author{
Erlinda A. Vasquez ${ }^{1,2,5}$, Dietmar Schmidt², Claus Peter Zebitz ${ }^{1}$, Uwe Beifuss², \\ Iris Klaiber ${ }^{2}$, Jurgen $\mathrm{Kroschel}^{3}$, and Remberto Patindol ${ }^{4}$ \\ ${ }^{1}$ Institut für Phytomedizin, Universität Hohenheim, 70599, Stuttgart, Germany \\ ${ }^{2}$ Bioorganische Chemie, Institut für Chemie, Universität Hohenheim, 70599, Stuttgart \\ ${ }^{3}$ Centro Internacional de la Papa, Lima, Peru \\ ${ }^{4}$ Department of Statistics, Visayas State University, Visca, Baybay, Leyte, Philippines \\ ${ }^{5}$ Permanent Address: Philippine Root Crop Research \& Training Center, Visayas State \\ University, Visca, Baybay, Leyte 6521-A, Philippines
}

\begin{abstract}
Structure-activity and species specificity of the three synthetic sweetpotato weevil pheromones, $(Z)-3$-dodecenyl-(E)-2-butenoate of $C$. formicarius, dodecyl- $(E)-2-$ butenoate of $C$. brunneus and decyl-(E)-2-butenoate $C$. puncticollis and their corresponding precursor free alcohols and trans-crotonic acid were assayed on virgin males of the three weevil species in the laboratory using one-arm olfactometer with bidirectional airflow. Each of the sex pheromones was specific to its conspecific males, however, a pheromone of a particular species may become active to another species only at higher amount to elicit the same degree of response. The free alcohol precursor of the pheromone of $C$. formicarius, 3-Z- dodecen-1-ol, showed sexual stimulation on $C$. brunneus and $C$. puncticollis while dodecan-1-ol functioned as an aggregation compound. The decan-1-ol, precursor of C. puncticollis pheromone, had the lowest attraction index regardless of weevil species tested. Males of $C$. formicarius and $C$. brunneus exposed to trans-crotonic acid performed a complete series of mating behavior
\end{abstract}

Keywords: Cylas formicarius, Cylas brunneus, Cylas puncticollis, female sex pheromones, crotonic acid, olfactometer assay, pheromone gland, chemical profile, GC-MS

Correspondence: E. A. Vasquez. Address: Philippine Root Crop Research 7 Training Center, Visayas State University, Visca, Baybay, Leyte 6521-A,Philippines. E-mail:lindvasq@yahoo.com. DOI: $10.32945 /$ atr3122.2009 
from antennae elevation to copulation while C. puncticollis exhibited the initial stage of mating behavior but copulation was not reached. This indicates that the crotonate part of the ester played a crucial role in activity of sex pheromone of the sweetpotato weevils. The unsaturation in the aliphatic chain was only important in $C$. formicarius pheromone for higher level of attraction and not to the African weevil species. The dichloromethane extract of the pheromone glands containing the known sex pheromone at concentration much lower than the synthetic pheromone used had higher attraction index. This suggests the possibility of other compounds present in the pheromone bouquets working synergistically for increased sexual activity. In GC and GC-MS, other compounds were detected at higher amount than the identified pheromones which may play an important role in the attraction and successful mating of the Cylas spp.

\section{INTRODUCTION}

There are several insects recorded as pests of sweetpotato (Talekar, 1988; Chalfant et al, 1990). The sweetpotato weevils, Cylas spp. are considered the most problematic and a threat to sweetpotato (Ipomoea batatas Lam.) production worldwide. The female adults feed and lay eggs on the surface of mature vines and surface of enlarged tuberous roots and developing larvae tunnel and create tunnels into the mature vines or tuberous roots filled with frass. Infested tuberous roots have pungent odor and bitter taste due to the toxic sesquiterpene produced in damaged tissue in response to insect feeding which render them unfit for human and animal consumption (Akazawa et al, 1960; Uritani, et al, 1975, Sato et al., 1981). Yield losses of 60-97 \% have been reported (Jansson et al, 1987) and may even reach almost $100 \%$ on highly susceptible varieties especially during prolonged dry season. Due to cryptic behavior of these insects, controlling them using conventional insecticides proves difficult and growers in many countries resort to use cultural practices and to some extent in combination with biological control and sex pheromones (Jansson, 1991; Talekar and Lee, 1989). In recent years, some successes have been achieved with formulations utilizing pheromones for monitoring and control of sweetpotato weevil specially Cylas formicarius.

The female sex pheromone of $C$. formicarius elegantulus (Summers) was identified and synthesized as (Z)-3-dodecenyl-(E)-2butenoate (Heath et al, 1986; Heath et al., 1988). For the African species, C. puncticollis Boheman and C. brunneus (Olivier), their female sex pheromones were identified as decyl-(E)-2-butenoate and dodecyl-(E)-2- 
butenoate, respectively (Hall, unpublished as cited by Dowham et al, 1994).

The work of Heath et al (1986) on the isolation, identification and synthesis of the pheromone of sweetpotato weevil, Cylas formicarius elegantulus, paved to the successful monitoring and mass trapping of the management of this weevil species. However, the synthetic pheromones of African weevil species were not as efficient as those of $C$. formicarius for mass trapping in the field (Laboke et al, 2000; Dowham et al, 1999). The live trap of 10 virgin females even caught more than the synthetic pheromones even at high dose of $1 \mathrm{mg}$. This amount of synthetic pheromone corresponds to hundreds of female weevils to come up with the same amount of natural pheromone. Individual feral female is capable of releasing 5-20 pg.

The sex pheromone of $C$. formicarius has high rate of success in mass trapping the male weevils (Villacarlos et al, 1995; Sureda et al. 2006). However, the use of synthetic pheromones to control the African sweetpotato weevils was not able to take off in the field because of the low level of attraction. For instance, Dowham et al (1999) were able to collect only 5-25 adult males $C$. puncticollis and 2-27 adult male $C$. brunneus in traps baited with decyl butenoate and dodecyl butenoate at $1 \mathrm{mg}$, respectively, while almost 2000 adults of $C$. formicarius in traps baited with the same amount of (Z)-3-dodecenyl-(E)-2 butenoate.

To explain why the highest dose of the synthetic pheromone of $C$. brunneus and $C$. puncticollis used in the field evaluation was not able to effectively attract their conspecific males, a dose-response and structureactivity relationship in the three species of Cylas need to be reassessed. It is also necessary to identify the other compounds present in the pheromone gland of female weevils to better understand the higher trapping efficiency of live weevils than using the single component pheromone especially in the African weevil species.

The dose response and structure-activity relationship of the different weevil pheromones as well as their precursors may serve as basis in the future synthesis of sweetpotato weevil pheromone derivatives and the identity of the chemical composition of the pheromone gland for much improved and better efficacy formulation. 


\section{METHODOLOGY}

\section{Mass Rearing of Sweetpotato Weevils}

Initial cultures of sweetpotato weevils were supplied by the Philippine Root Crop Research \& Training Center, Philippines (C. formicarius) and CIP-Uganda, Africa (C. brunneus and C. puncticollis). The three species of sweetpotato weevils were continuously reared in the laboratory on commercially available sweetpotato, Baeuregard, at $26 \pm$ $2^{\circ} \mathrm{C}$ at $60 \pm 5$ relative humidity $(\mathrm{RH})$ under 14:10 (light-dark) photoperiod.

Adults of sweetpotato weevils (75 males and 75 females) were placed in each plastic rearing cage provided with fresh sweetpotato tuberous roots as feeding and oviposition substrate. The female adults were allowed to lay eggs for 2-3 days on the tuberous roots. The eggsladen tuberous roots were removed, wrapped in paper towel, incubated in rearing box until adult emergence. Adults emerging from the infested tubers were sexed immediately upon emergence before mating occurred. Adults produced during the first generation were used for mass rearing. Individuals produced from second and third generation were used for the assay and preparation of the crude pheromone extract.

\section{Extraction of Crude Extract of the Female Pheromone Gland of Sweetpotato Weevils for Olfactory Assay}

Pheromone crude extracts of each Cylas species were prepared from 1-wk old 5 and 10 virgin adult females pheromone glands. Applying pressure of the abdomen of the live female exposed the everted gland at the posterior end of the abdomen. The gland, a small portion of the oviduct, was carefully clipped using a fine-tipped needle and placed in tapered vial containing $50 \mu \mathrm{l}$ dichloromethane and soaked overnight. The supernatant liquid was removed, the glands rinsed with $50 \mu \mathrm{l}$ dichloromethane, the solvent removed and then combined with the previous supernatant liquid. The extract was concentrated to 10-15 $\mu 1$ and impregnated to $2-\mathrm{cm}$ dia. filter paper disc. Extraction was replicated three times. 


\section{Synthetic Pheromones and Precursor}

The synthetic (Z)-3-dodecenol (1) and the three weevil pheromones, (Z)-3-dodecenyl-(E)-2-butenoate (2), dodecyl-(E)-2butenoate (3) and decyl-(E)-2-butenoate (4) not available commercially were synthesized by Steglich esterification (Neises and Steglich, 1978) and the other compounds [alcohol precursors, dodecanol (5) and decanol (6); d trans-crotonic acid (7); and those reagents needed in the synthesis of the sweetpotato weevil pheromones] were purchased from Lancaster, ICI, and Sigma Aldrich (Fig. 1). Details for the synthesis are reported in another paper.

\section{Olfactometer Assay for Dose-Response and Structure-Activity Study}

Serial dilutions of the synthetic sweetpotato weevil pheromones and their precursors were prepared in dichloromethane to dispense 0.001 , $0.01,0.1,1$ and 10 ug per $100 \mathrm{ul}$ which were separately impregnated in 2 $\mathrm{cm}$ dia filter paper discs. The positive controls consisted of filter paper discs impregnated with five and 10 virgin female equivalent of each weevil species and negative control with dichloromethane alone. Treated paper discs with known dosage of the test material were allowed to dry and placed in sealed $3-\mathrm{cm}$ dia petri dish 30 minutes before use.

The assay was conducted using a $40 \mathrm{~cm}$-single arm olfactometer with bidirectional airflow (Fig. 2) (Romeis and Zebitz, 1997). The airflow was adjusted to $400 \mathrm{ml} / \mathrm{min}$ for each arm. Treated- and control filter paper disc were placed separately in Erlenmeyer flask connected to one end of the single arm olfactometer by silicon tubing.

During the test inexperienced virgin male weevils were introduced singly into the center of the olfactometer and then the airflow was started. After the weevil had crossed the "final choice line" in one of the two arms, i.e. $5 \mathrm{~cm}$ away from the center of the tube, it was considered to have positive response. Uncommitted weevil staying within the $5 \mathrm{~cm}$ distance from the center of the tube was treated as non-responder. The test was done in three replicates with 20 weevils per replicate. 
<smiles>CCCCCCCCC=CCC(O)I</smiles>

(Z)-3-Dodecen-1-

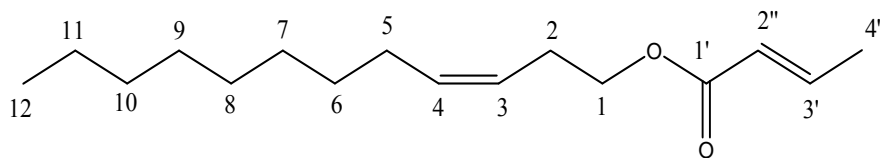

(Z)-3-Dodecenyl-(E)-2-

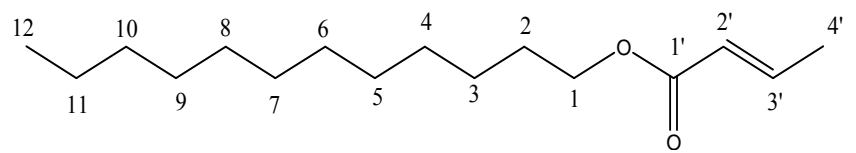

Dodecyl-(E)-2-

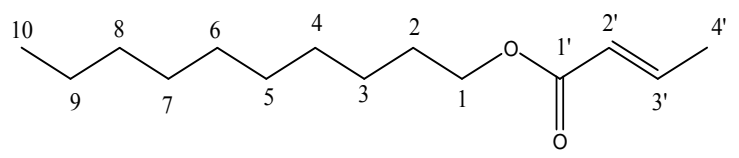

Decyl- $(E)-2-$<smiles>[1H]CC=CCCCCCCCC(O)I</smiles>

Dodecan-1-<smiles>CCCCCCCCCC(O)I</smiles>

Decan-1-<smiles>C/C=C/C(=O)O</smiles>

trans-crotonic acid

Fig.1. Synthetic sweetpotato weevil pheromones and their precursors. 


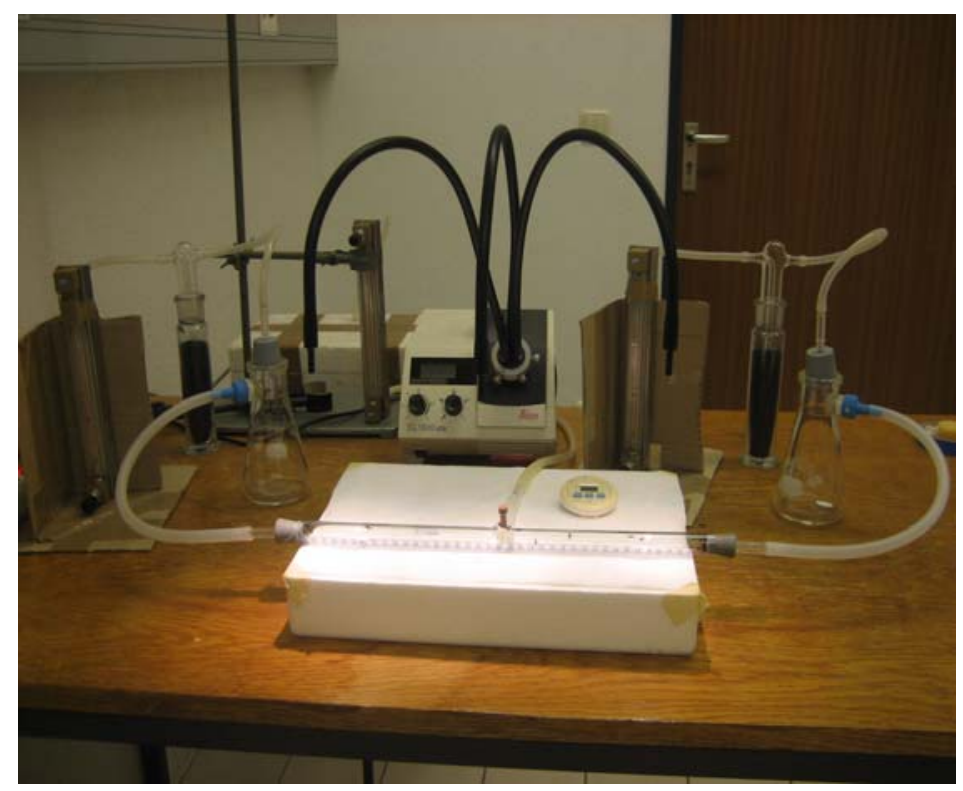

Figure 2. One-arm olfactometer with bidirectional air flow. 
The glass tube was rinsed with $96 \%$ ethanol every after 10 weevils were introduced to remove traces of compounds which may have been left by the previous weevils. Glass and silicon tubes were rinsed twice when new set of substance was tested. The Erlenmeyer flasks were changed and new treated filter paper discs were placed every replicate tested. Weevils were only used once and discarded. All tests were done under uniform illumination supplied by an illuminator (Leika $1500 \mathrm{KL}$ ).

The attraction index (AI) was corrected using Schneider-Orelli formula as: Corrected $\% \mathrm{AI}=\%$ weevil responded in treated $-\%$ weevil responded in control / $100-\%$ weevil responded in control x 100 . The data was subjected to statistical analysis using Tukey's test.

\section{Analysis and identification of compounds in pheromone gland}

The crude pheromone extract of each Cylas species was analyzed by gas chromatography and gas chromatography-mass spectrometry on a Finnigan Polaris Q GC/MS Ion Mass Spectrometer using a BPX5 capillary column ( $30 \mathrm{~m} \times 0.32 \mathrm{~mm}$ ID, $0.25 \mu \mathrm{m}$ film). Using helium as carrier gas the column was operated with temperature programmed from $50^{\circ} \mathrm{C}$ for 5 minutes and raised to $280^{\circ} \mathrm{C}$ at $10^{\circ} \mathrm{C} / \mathrm{min}$. with 15 minutes holding time and raised again to $300^{\circ} \mathrm{C}$ at $10^{\circ} \mathrm{C} / \mathrm{min}$ and holding time of $10 \mathrm{~min}$. Three injections of $0.5 \mu \mathrm{l}$ from $10 \mu \mathrm{l}$ concentrated dichloromethane extract of 100 one-week old virgin females were done.

The compounds present in the extract were identified by comparing their retention time and mass spectra with synthetic standards subjected under the same GC-MS conditions and also with the database NIST library.

\section{RESULTS}

\section{Dose-Response and Structure-Activity Relationship Study}

Results of olfactometer assay of the three sweetpotato weevil pheromones as well as their precursors, their respective alcohol and transcrotonic acid, are presented in Figs. 3a-3c. Attraction of the different pheromones and their alcohol precursors as well as the trans-crotonic acid at different dosages was highly significant. Regardless of the pheromones used, dosages beyond $100 \mathrm{ng}$ showed negative response to the conspecific males. In all cases male weevils need a very minute amount of pheromone 
to elicit sexual activity. As low as $1 \mathrm{ng}$ of (Z)-3-dodecenyl-(E)-2butenoate (2) was needed to produce optimum level of attraction to $C$. formicarius while $100 \mathrm{ng}$ of the amount dodecyl (E)-2-butenoate (3) and $1,000 \mathrm{ng}$ were required to elicit the same level of attraction to $C$. brunneus and C. puncticollis, respectively. Except for C. formicarius, the minimum effective dose of each of the pheromone was less attractive than the crude extract of 5 or 10 pheromone glands of one week-old virgin female. The three female sex pheromones $(2,3,4)$ were not only active on their corresponding conspecific males but also on other species. However, higher amount of pheromone is needed to attract males of other species. Sex pheromones 2 and $\mathbf{3}$ were active on the three weevil species but pheromone 4 was only active on $C$. formicarius and C. puncticollis. These findings are in agreement with those of Dowham et al (1999).

The free alcohols precursors of the three pheromones, (Z)-3dodecen-1-ol, dodecan-1-ol and decan-1-ol, also exhibited biological activity to male weevils but to a limited degree. The three alcohols attracted more $C$. formicarius and C. puncticollis (35-60\%) than $C$. brunneus (10-25\%) at 1-10 ug. The latter species was not even receptive to the alcohol precursor of its own pheromone.

The insects were also observed to have longer feigning mechanism than those exposed to sex pheromones before they started to react to the source of stimulus. Many alcohols in the C10 to C18 range, and their short-chain acid esters are potent sex or aggregation pheromones. They are mainly found as components of specialized defensive glands, pheromone glands or glands of the reproductive system (http://www.cyberlipid.org/simple/simp0003.htm). In separate studies on non-air displacement test using open arena technique, it was observed that male weevils exposed to (Z)-3-dodecen-1-ol portrayed attempted mating with each other while those on dodecan-1-ol and decan-1-ol tended to aggregate themselves.

The primary fatty alcohols under study also exist either as major or minor components of pheromone bouquet of several insects (El Sayed, 2007). For instance (Z)-3-dodecenol is an active trail pheromone of four species of war-like termites, Macrotermes annandalei Silvestri, $M$. barneyi Light, $M$. bellicosus Smeathan and $M$. subhyalinus as well as the subterranean termites, Odontotermes hainanensis and O. maesodensis (Peppuy et al 2001a; 2001b). Dodecan-1-ol is present in sex pheromone blends of a wide range of insect groups. It is reported as sex pheromone on 


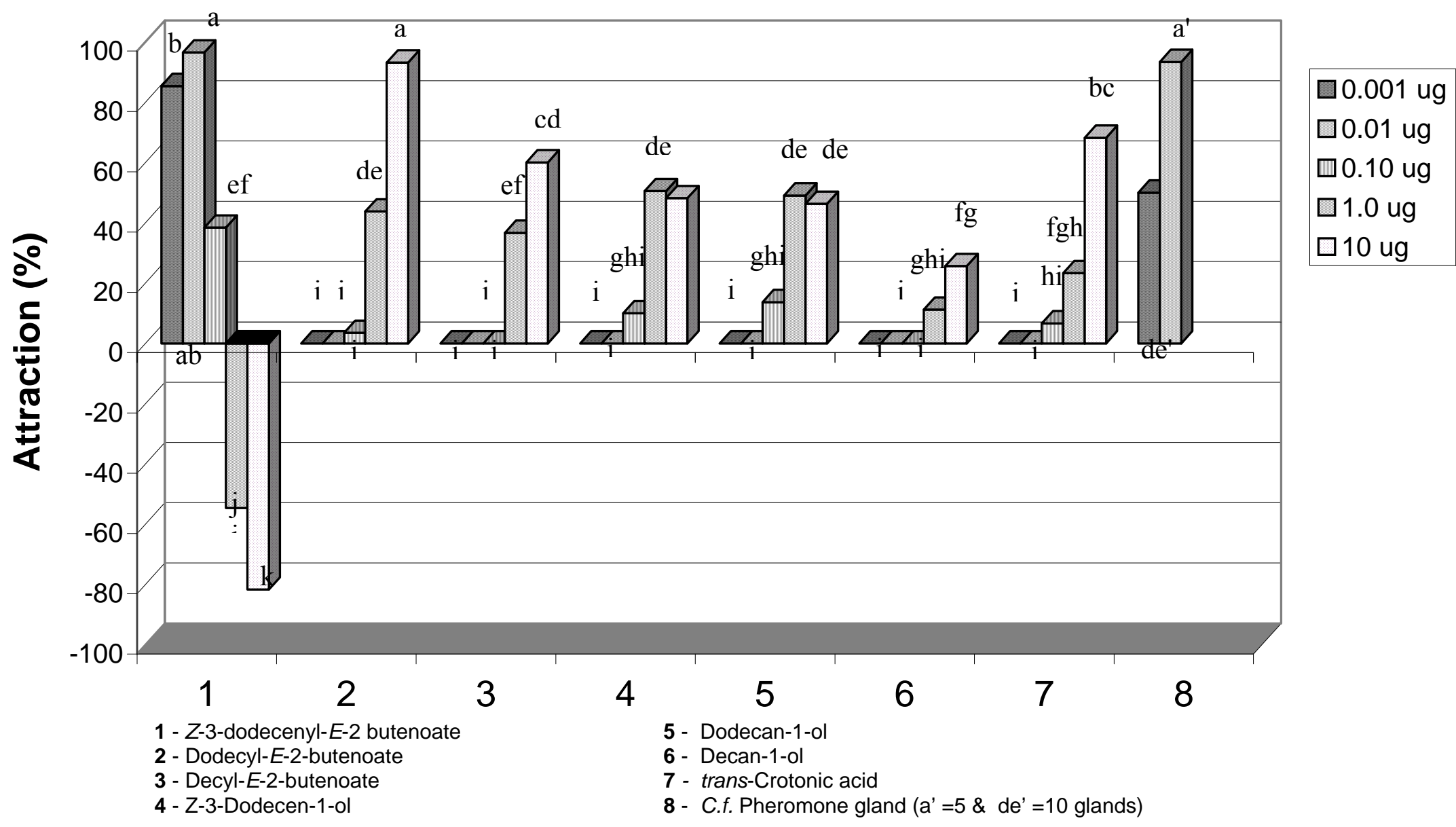

Fig. 2a. Attraction of male Cylas formicarius (C.f) to the three female sweetpotato weevil sex pheromones, their precursors and the crude extract of pheromone gland. 


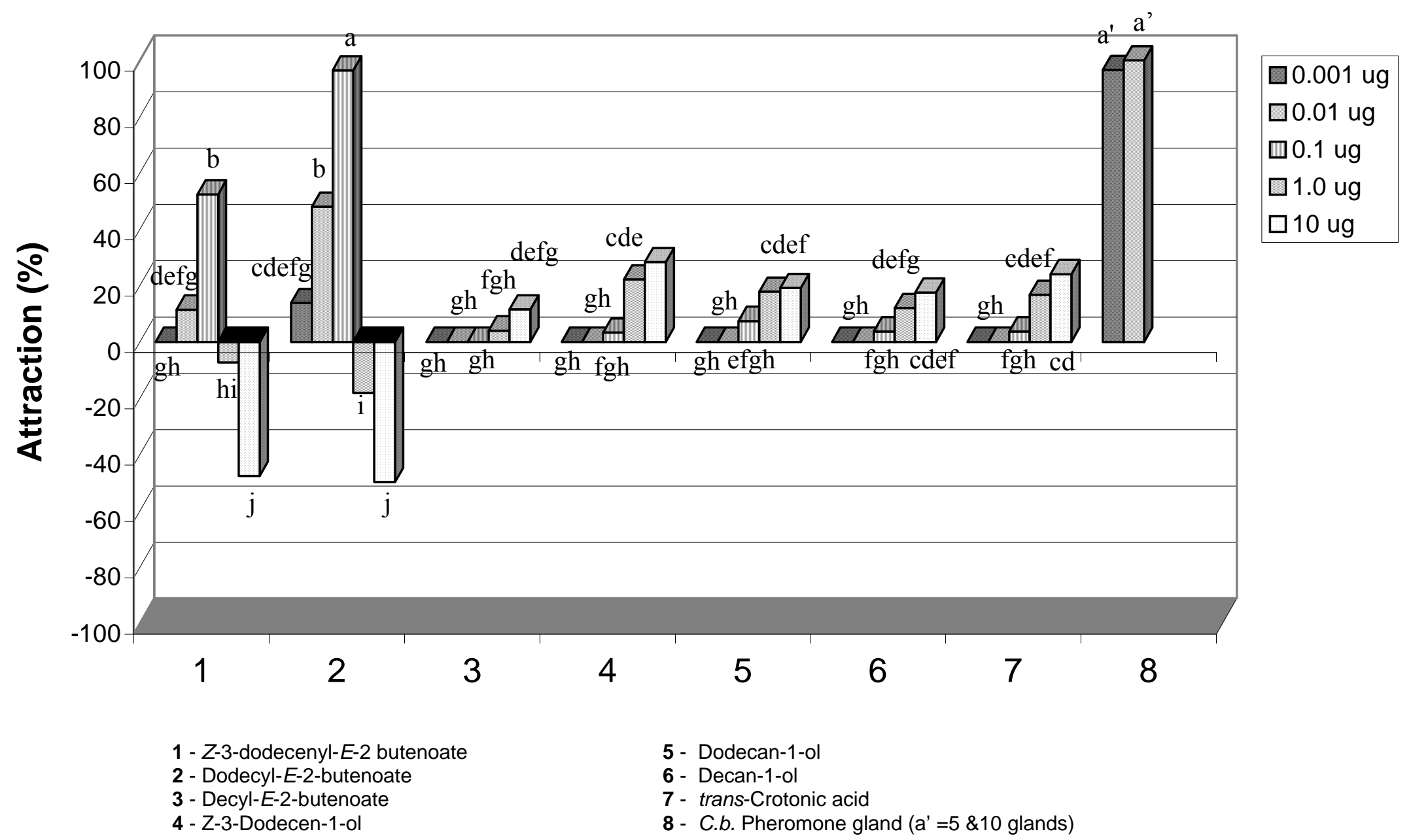

Fig. 2b. Attraction of male Cylas brunneus (C.b) to the three female sweetpotato weevil sex pheromones, their precursors and the crude extract of the pheromone gland. 


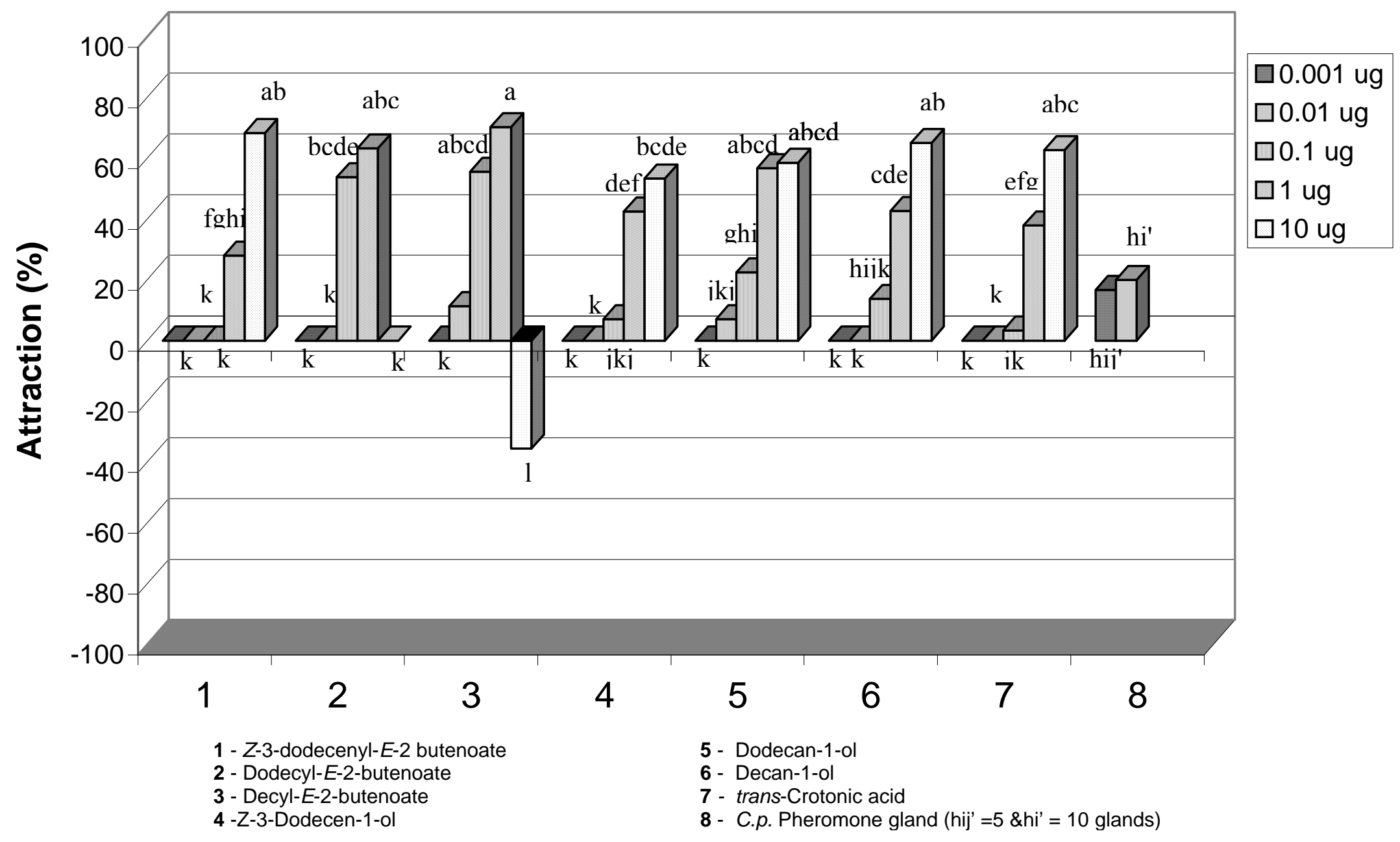

Fig. 2c. Attraction of male Cylas puncticollis $s(C p)$ to the three female sweetpotato weevil sex pheromones, their precursors and the crude extract of the pheromone gland. 
turnip moth, Agrotis segetum Denis and Schiffermüller (Lofstedt et al, 1986); cranberry fruitworm, Acrobasis vaccinii Riley (McDunough et al, 1994); pine shoot moth, Ryacionia boulinana Schiffermüller (Gray, et al, 1984) and pine tipmoth, $R$. frustrana Comstock (Hill et al, 1981); coddling moth, Cydia pomonella Linnaeus (Wittzgal et al 2000; El Sayed et al, 1999; Causse, et al, 1988; Bartell et al, 1988; Einhorn et al, 1986 Arn et al, 1985), grapeberry moth, Endopiza viteana Clemens (Witzgall et al, 2000) and Celypha pseudolexicola Liu (Tang et al, 1994); coffee totrix, Homona coffearia Neitner (Roelofs and Brown, 1982; Kochansky et al, 1978); avocado leaf roller, Homona spargotis Meyrick (Whittle et al, 1987); European cornborer, Ostrinia nubilalis Guenee (Struble, et al, 1987); trail pheromone of yellow necked dry-wood termite, Kalotermes flavicollis Fabricius (Klochkov and Puschin, 1989); attractant of African malaria mosquito, Anopheles gambiae Giles (Meijerink et al, 2000); and marking pheromone of Alpino bombus males, Bombus balteatus Dahlbom (Svennson and Bergström, 1979). Decan-1-ol on the other hand, is not as conspicuous as dodecan-1-ol. It is one of the components of the trail pheromone of yellow necked dry-wood termite, K. flavicollis Fabricius (Klochkov and Puschin, 1989); and sex pheromone of A. segetum Denis and Schiffermüller (Lofstedt et al, 1986), C. pomonella Linnaeus (Witzgall et al, 2000, Arn, 1985) and Guerney carpet beetle, Anthrenus sarnicus Mroczkowski (Finnigan and Chambers, 1993).

The trans-crotonic acid appeared to function also as sex pheromone. Male weevils behaved similarly as those exposed to either the pure sex pheromones or the crude extract of the pheromone gland. However, the activity was more pronounced on $C$. formicarius and $C$. puncticollis reaching $60 \%$ attraction at 10 ug than on $C$. brunneus with only $20 \%$ attraction at the same amount of trans-crotonic acid. This compound was also reported to attract males of spider, Neriene montana (Schulz, 1997).

Based on the results, both the aliphatic alcohol and the crotonate of the sweetpotato weevil pheromone ester molecules are responsible for attracting the conspecific males especially in $C$. formicarius and $C$. puncticollis. The number of carbon atoms in the aliphatic chain also played an important role in the activity of sweetpotato weevil pheromone. C. formicarius and C. brunneus males became active when exposed to pheromone with $12 \mathrm{C}$ aliphatic side chain and less receptive to those with lower 10C number. In electrophysiological tests of Sureda et al (2006), the crotonate function in the pheromone structure of $C$. formicarius proved to be critical for activity since regular depolarizations $(0.6-0.8 \mathrm{mV})$ were obtained with puffs on $1 \mu \mathrm{g}$ of the attractant, but not with puffs of the formate, acetate, propionate, or butyrate analogue of the pheromone. As an 
individual compound, the precursor alcohols and trans-crotonic acid had little pheromone activity on C. brunnneus.

The different weevil species were not strictly pheromone specific. Each species is still receptive to pheromones of other species but requires a higher amount to elicit the same level of attraction. The higher selectivity observed is consistent with Roelofs' (1978) threshold hypothesis, by which higher release rates are required to attract species with the "wrong pheromone blend".

\section{Chemical Composition of the Pheromone Gland Crude Extract}

The high activity of the crude extract of the pheromone glands from virgin females suggests that other compounds may be present and contribute some synergistic activities. These compounds may be constituents of the pheromone bouquets of the female sweetpotato weevil. For this reason the crude extract was examined and analyzed.

Based on GC-MS (Figs. 3a \& 3b; Table 1) the pheromone gland of each Cylas species contained several compounds other than the sex pheromones mentioned. However, the active sex pheromone is highly species specific. Only one type of the known active pheromone was present per species. The other compounds present especially those which are less volatile than the identified sex pheromones may work synergistically pheromones to have higher activity. The other compounds of less volatility may function at closer range. Insects rarely rely on single odors as key stimuli releasing a specific behavioral sequence. Whether the odor cues are involved in food, partner or oviposition site search, they usually come as a bouquet composed of a number of chemical constituents (Hansson and Anton, 2000). The response of insect towards pheromone blends can either be stronger than the summed response to a single component working as synergist or weaker as an agonist. In a number of moth species, neurons that show no or a very low response to a single pheromone component are strongly excited by the complete pheromone blend have been reported (Hansson and Anton, 2000).

Among the three species under study, the pheromone gland of $C$. puncticollis contained the least of the identified sex pheromone while that of C. brunnesus contained the highest (Figs. $4 \mathrm{a}$ and $4 \mathrm{~b}$, Table 1). The very minute amount of decyl-(E)-butenoate may explain the very low attraction index of the crude extract as compared to the crude extract of the other species. On the other hand, the high amount of dodecyl $(E)-2$ - butenoate in C. brunneus gland is directly correlated to its high level of activity. The 
presence of (Z)-3-dodecenyl-(E)-2-butenoate in the pheromone gland of C. formicarius was also considerably low. However, the males of this species need a very minute amount of the female sex pheromone as low as $100 \mathrm{pg}$ to $1 \mathrm{ng}$ to become sexually active. This observation is in agreement to the high attraction of the crude extract from 5-10 virgin females. A virgin female is capable of emitting $20 \mathrm{pg}$ of the said pheromone (Sureda et al 2006).

If the amount of the pheromone present in the pheromone gland is also taken in consideration, it is still much lower than the minimum effective concentration to attract C. brunneus. Again such result indicates that other compounds may be involved in the whole series of mating behavior of this species. 
Table 1. Retention time (RT), peak area and identification of compounds of dichloromethane crude extract of one-week old female pheromone gland of C. formicarius (C.f), C. brunneus (C.b.) and C. puncticollis (C.p.).

\begin{tabular}{|c|c|c|c|c|c|c|}
\hline \multirow[t]{2}{*}{ RT } & \multirow[t]{2}{*}{ Compound } & \multirow{2}{*}{$\begin{array}{l}\text { Chemical } \\
\text { Formula }\end{array}$} & \multirow[t]{2}{*}{ MW } & \multicolumn{3}{|c|}{ Peak Area (\%) } \\
\hline & & & & C.f. & $C b$ & C. $p$. \\
\hline $11.61-11.66$ & 1-(2-Methoxymethyl-cyclohexane & $\mathrm{C} 9 \mathrm{H} 14 \mathrm{O}$ & 138 & 0.36 & - & 0.14 \\
\hline $13.52-13.54$ & 1,2 Dimethoxybenzene & $\mathrm{C} 8 \mathrm{H} 10 \mathrm{O} 2$ & 138 & - & 0.32 & 0.08 \\
\hline $18.10-18.16$ & 3,5-bis(1,1-dimethoxyethyl-phenol & $\mathrm{C} 14 \mathrm{H} 22 \mathrm{O}$ & 206 & - & 0.41 & - \\
\hline $19.65-19.69$ & Decyl $(E)$-2-butenoate & $\mathrm{C} 14 \mathrm{H} 26 \mathrm{O} 2$ & 226 & - & - & 0.06 \\
\hline $21.63-21.68$ & (Z)-3-Dodecenyl-(E)-2-butenoate & $\mathrm{C} 16 \mathrm{H} 28 \mathrm{O} 2$ & 252 & 0.20 & - & - \\
\hline $21.85-21.88$ & Dodecyl-(E)-2-butenoate & $\mathrm{C} 16 \mathrm{H} 30 \mathrm{O} 2$ & 254 & - & 2.02 & - \\
\hline $23.21-23.34$ & Palmitic acid & $\mathrm{C} 16 \mathrm{H} 32 \mathrm{O} 2$ & 256 & 0.42 & 9.86 & - \\
\hline $24.78-24.79$ & Methyl linoleate & $\mathrm{C} 19 \mathrm{H} 34 \mathrm{O} 2$ & 294 & - & - & 3.01 \\
\hline $24.88-24.93$ & Ethyl linoleate & $\mathrm{C} 20 \mathrm{H} 36 \mathrm{O} 2$ & 308 & 2.97 & - & 0.75 \\
\hline $24.92-24.97$ & Oleic acid & $\mathrm{C} 18 \mathrm{H} 34 \mathrm{O} 2$ & 282 & - & 13.70 & - \\
\hline $25.05-25.08$ & Ethyl oleate & $\mathrm{C} 20 \mathrm{H} 38 \mathrm{O} 2$ & 310 & 7.48 & - & 1.37 \\
\hline $25.14-25.18$ & Stearic acid & $\mathrm{C} 18 \mathrm{H} 36 \mathrm{O} 2$ & 284 & - & 23.14 & 0.24 \\
\hline $25.19-25.22$ & Hexadecenamide & C17H33NO & 279 & - & 4.69 & - \\
\hline $26.77-26.82$ & Octadecenamide & C18H35NO & 281 & 1.09 & - & - \\
\hline $27.47-27.52$ & Pentacosanol & $\mathrm{C} 25 \mathrm{H} 15 \mathrm{O}$ & 350 & - & 1.59 & 0.13 \\
\hline $27.66-26.69$ & Unidentified & & & 0.96 & - & 0.64 \\
\hline $27.90-27.94$ & Unidentified & & & 0.82 & - & 1.94 \\
\hline $28.07-28.11$ & Unidentified & & & - & - & 0.57 \\
\hline $28.12-28.22$ & Unidentified & & & - & - & 0.98 \\
\hline $28.46-28.48$ & Stearyl monoglyceride & $\mathrm{C} 21 \mathrm{H} 44 \mathrm{O} 3$ & 344 & 0.65 & 0.58 & 0.28 \\
\hline $29.03-29.06$ & Pentacosane, 9 methyl & $\mathrm{C} 26 \mathrm{H} 56$ & 366 & 3.37 & 3.80 & 6.30 \\
\hline $29.14-29.29$ & Heptacosanol & $\mathrm{C} 27 \mathrm{H} 54 \mathrm{O}$ & 385 & - & 13.56 & 15.24 \\
\hline $29.16-29.22$ & Heptacosene & $\mathrm{C} 27 \mathrm{H} 54$ & 378 & 13.04 & - & 8.47 \\
\hline $29.33-31.42$ & Heptacosane & $\mathrm{C} 27 \mathrm{H} 56$ & 380 & 4.85 & - & 2.32 \\
\hline $29.61-29.63$ & Unidentified & & & - & - & 3.39 \\
\hline $29.73-28.80$ & Unidentified & & & - & - & 0.78 \\
\hline $29.89-29.99$ & Unidentified & & & - & - & 2.02 \\
\hline $30.03-30.11$ & Unidentified & & & - & - & 5.45 \\
\hline $30.17-30.30$ & Unidentified & & & - & - & 0.98 \\
\hline $30.34-30.41$ & Octacosene & $\mathrm{C} 28 \mathrm{H} 56$ & 392 & - & - & 0.80 \\
\hline $30.41-30.48$ & Octacosane & C28H58 & 400 & 0.61 & - & 0.43 \\
\hline $30.56-30.76$ & 13-Dococenamide & $\mathrm{C} 22 \mathrm{H} 43 \mathrm{NO}$ & 337 & 2.49 & 0.53 & 3.24 \\
\hline $31.19-31.28$ & Hexacosane, 9-octyl & & & 0.53 & 0.34 & 2.30 \\
\hline $31.44-31.51$ & Nonacosene & C29H58 & 406 & 16.54 & 1.17 & 6.81 \\
\hline $31.52-31.60$ & Nonacosane & С29H60 & 408 & - & - & 1.52 \\
\hline $36.69-36.85$ & Cholesterol & $\mathrm{C} 27 \mathrm{H} 46 \mathrm{O}$ & 386 & 16.23 & 0.53 & 17.36 \\
\hline $39.42-39.65$ & Cholest-5-one & $\mathrm{C} 27 \mathrm{H} 46 \mathrm{O}$ & 386 & - & 1.54 & - \\
\hline
\end{tabular}




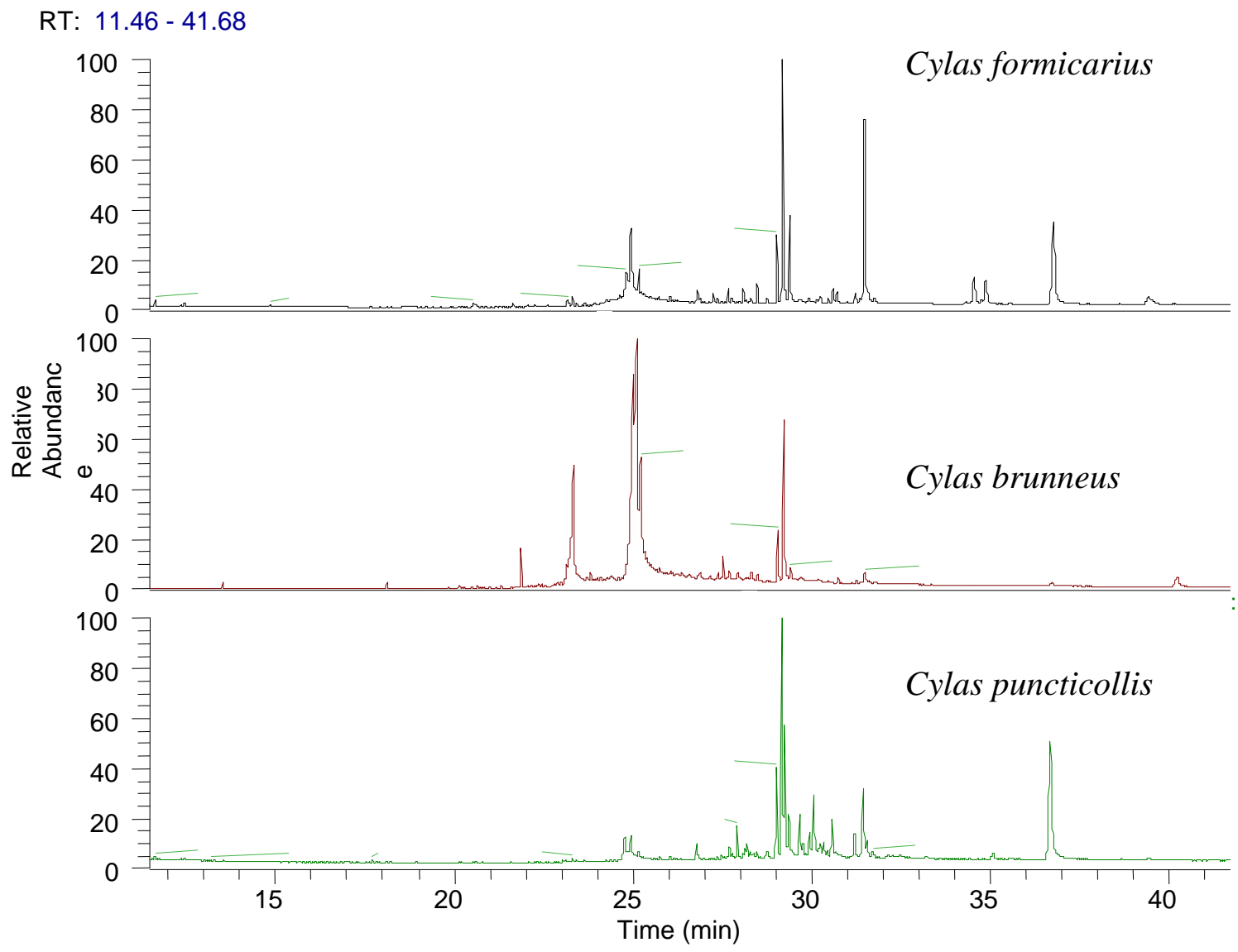

Fig. 4a Total ion chronıaugram of the dichlorome unane crude extract of the pheromone glands of one week-old virgin females of three Cylas species. See Table 1 for peak identity based on RT of natural compound and synthetic standards and comparison of values with NIST library. 
RT: $12.14-23.04$

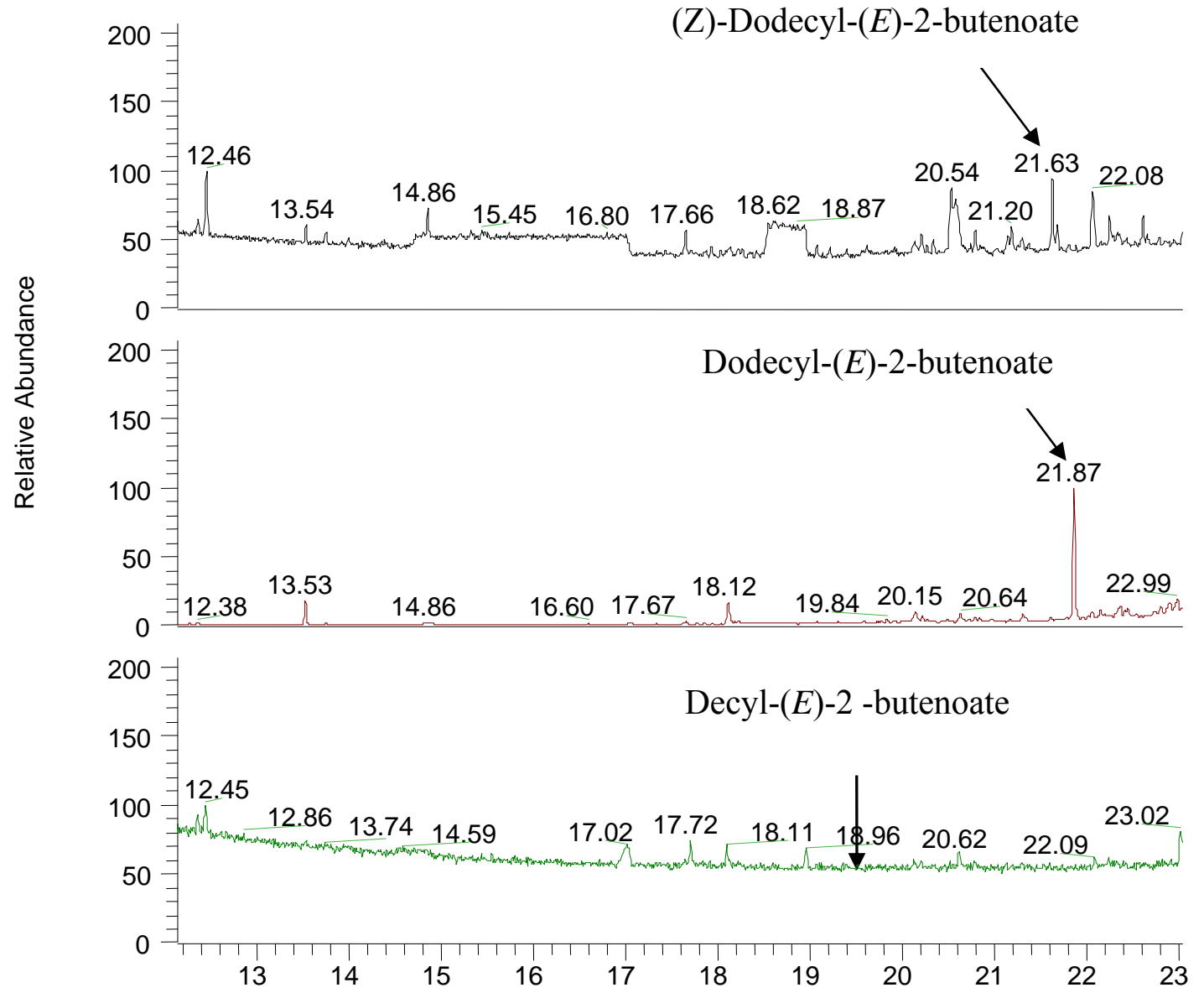

Fig. 4b. Total ion chromatogram of the dichloromethane crume (min) extract of the pheromone glands of one week-old virgin females of three Cylas species showing retention time of the sex pheromone. 
The other compounds detected range from low molecular (C8 and C9) volatile compounds to less volatile C18- C20 aliphatic saturated and unsaturated hydrocarbons, acids, esters and amides. The major components $(>1 \%)$ observed were ethyl linoleate, ethyl oleate, and octadecenamide from C. formicarius; octadecanoic acid, oleic acid, and heptadecenamide from C. brunneus; and octadecenoic acid methyl ester, ethyl oleate and octadecenamide from C. puncticollis (Table 1). They may be components of the sex pheromone bouquets of sweetpotato weevils or precursors of the sex pheromone. These compounds are also active as sex pheromones of other insect species. Ethyl linoleate, ethyl oleate and oleic acid are components of the male and female aggregation pheromone of Kaphra beetle, Trogoderma granarium (Ikan et al 1969, Cohen et al, 1971) and ethyl linoleate is present in sexually deceptive orchid attracting hymenopteran pollinator Campososcolia ciliata (Ayasi et al 2003). Octadecanoic acid is a sex pheromone of several lepidopterans and hymenopterans. It is also one of the components of the aggregation pheromone of Khapra beetle (Cohen et al 1971). Cuticular hydrocarbons up to C-29, cholesterol and cholest-5-3-one were also detected at higher concentrations. A number of cuticular hydrocarbons are components of contact sex pheromones (El Sayed, 2007).

\section{DISCUSSION}

The olfactometer assay of the three pheromones on three Cylas species indicated higher dosage of dodecyl (E)-3-butenoate and decyl (E)2-butenoate is needed to obtain high trapping rate of $C$. brunneus and $C$. puncticollis, respectively, to obtain comparable results with that of (Z)-3dodecenyl-(E)-2-butenoate to $C$. formicarius. Increasing the pheromone dosage by $10-100 \mathrm{X}$ higher than what has been used in trapping $C$. brunneus and C. puncticollis may result to optimum field mass trapping.

The sex pheromones of C. brunneus and C. puncticollis as suggested by Dowham et al. (1999) to probably consist of single component may not hold true since in their field studies they found that lures of 10 live virgin females of $C$. brunneus and $C$. puncticollis attracted more males than $0.1-1 \mathrm{mg}$ of the synthetic pheromones. The hypothesis of a single-component pheromone is an exceptions rather than the rule (Tumlinson and Lee, 1987). The earlier work of Silverstein (1966) in which three terpenes were identified as synergistic blends for Ips paraconfusus indicated that multi-component are used by Coleoptera. Since then a number of pheromone blends not only in Coleoptera but also in other insect orders have been identified (El Sayed, 2005). For Cylas 
spp., it is possible that other less volatile compounds may be present that may function as sex pheromone or may work as synergists with the identified pheromones but were not adsorbed by SPME.

Lipids are excellent candidates for signaling purposes. The fatty acid constituents have well-defined structural flatness, such as cis-double bonds in particular position, which can carry information by binding selectively to the specific receptors. In esterified form, they can infiltrate membrane or to be translocated across them to carry signals to other cells. During transport they are usually bound to proteins so their effective solution concentration are very low, as they are can be considered to be inactive until they reach the site of action and encounter the appropriate receptors (www.lipidlibrary.co.uk/lipids/whatdo/index.htm).

The higher selectivity observed is consistent with Roelofs' (1978) threshold hypothesis, by which higher release rtes are required to attract species with the "wrong pheromone blend". Most sex or aggregation pheromones of insects consists of two or more compounds that alone have moderate or no activity but released together are synergistic in eliciting maximum behavioral response (Silverstein and Young, 1976; Silverstein, 1981; Cardé and Baker, 1984; Byers, 1989).

The prerequisite for olfactory reception is the recognition of stimulus molecules thought to bind with acceptor sites in the dendritic membrane, in a fashion similar to that of the enzyme-substrate complex (Kaissling, 1974). The affinity of a stimulus molecule to an acceptor is considered to be specifically related to its chemical structure. The specific binding with acceptor implies a definite relationship between chemical structures of stimulus molecule and their biological activity, which is manifested in the insect's response to odor component (Visser, 1986).

\section{ACKNOWLEDGMENT}

The senior author is grateful to the Alexander von Humboldt Foundation for the long term research fellowship and to DAAD for support during the initial phase in the synthesis of the pheromone of Cylas formicarius during a short term research visit. 


\section{REFERENCES}

ARN, H., GUERIN, P.M., BUSER, H.R., RAUSCHER, S., and MANI, E. 1985. Sex pheromone blend of the codling moth, Cydia pomonella: evidence for a behavioral role of dodecan-1-ol. Experientia. 41:1482-1484.

AZAKAWA, T.L., URITANI, I. and KUBOTA, H. 1960. Isolation of ipomeamarone and two coumarins derivatives from sweetpotato roots injured by the weevil Cylas formicarius elegantulus. Arch. Biochem. Biophys. 88:150-156.

BYERS, J.A. 1989. Chemical ecology of bark beetles. Experientia 45:271-283.

BYERS, J.A. 1992. Trends in chemical ecology revealed with a personal computer program for searching data base of scientific references and abstracts. J. Chem. Eol. 18: 1481-1495.

CARDÉ, R.D. and BAKER, T.C. 1984. Sexual communication and pheromones. pp. 355- 383. in W.J. Bell and R.T. 8eds.) Chemical Ecology of Insects. Chapman and Hall. London

CAUSSE, R., BARTHES, J., WITZGALl, P., EINHORN, J. 1988. Secondary components of the sex pheromone of the codling moth, Cydia pomonella L. (Lepidoptera, Tortricidae). III. Synergistic effect of dodecanol in field trapping. C.R. Acad. Sci. Paris. Ser. 3. 306:125-128.

CHALFANT, R.B., JANSSON, D.R., SEAL, D.R., and SHALK, J.M. 1990. Ecology and management of sweet potato insects. Annu. Rev. Entomol. 35: 157-180.

COHEN, E., IKAN, R., and SULOV, A. 1971. Response of the females of Trogoderma granarium (Coleoptera, Dermestidae) to cuticular free fatty acids. Entomol. Exp. Appl. 14:315-318.

DOWHAM, M.C.A., SMIT, N. E. J. M., LABOKE, P.O., HALL, D.R.., FARMAN, D.I., BRAUN, A., and ODONGO, B. 1999. Specificity of response to sex pheromones among sweetpotato weevils, Cylas puncticollis and C. brunneus. J. Chem. Ecol. 23(3): 591-608.

EL-SAYED, A.M., BENGTSSON, M., RAUSCHER, S., LÖFQVIST, J., and WITZGALL, P. 1999. Multicomponent sex pheromone in codling moth (Lepidoptera: Tortricidae). Environ. Entomol. 28:775-779

EL- SAYED, A.M. 2007. The Pherobase: Database of Insect Pheromones and Semiochemicals. http://www.pherobase.com. (C2003-2007. The Pherobase. Ashraf M. El-Sayed.

FINNEGAN, D.E., and CHAMBERS, J. 1993. Identification of the sex pheromone of the Guernsey carpet beetle, Anthrenus sarnicus Mroczkowski (Coleoptera: Dermestidae). J. Chem. Ecol. 19:971-983.

GRAY, T.G., SLESSOR, K.N., SHEPHERD, R.F., GRANT, G.G., and MANVILLE, J.F. 1984. European pine shoot moth, Rhyacionia buoliana (Lepidoptera: Tortricidae): identification of additional pheromone components resulting in an improved lure. Can. Entomol. 116:1525-1532.

HANSSON, B.S. and ANTON, S. 2000. Function and morphology of the antenna lobe. New development. Ann. Rev. Entomol. 45:203-231.

HEATH, R.R., COFFELT, J.A., PROSHOLD, F.I., SONNET, P.E., and TUMLINSON, J.H. 1986. Identification of sex pheromone produced by female sweetpotato weevil, Cylas formicarius elegantulus (Summers). J. Chem. Ecol. 12:1489-1503.

HEATH, R.R., COFFELT, J.A., PROSHOLD, F.I., JANSSON, R.K., and SONNET, P.E. 1988. (Z)-3-Dodecen-1-ol (E)-2-butenoate and its use in monitoring and in controlling the sweetpotato weevil. US Patent 4,732,756. 
HILL, A.S., BERISFORD, C.W., BRADY, U.E., and ROELOFS, W.L. 1981. Nantucket pine tip moth, Rhyacionia frustrana: identification of two sex pheromone components. J. Chem. Ecol. 7:517-528.

IKAN, R., BERGMANN, E.D., YINON, U. and SULOV, A. 1969. Identification, synthesis and biological activity of an assembling scent from the beetle Trogoderma granarium. Nature 223:317

JANSSON, R.K., BOYSEN, H.H. and SORENSEN, K.A. 1987. Within vine distribution and damage of sweetpotato weevil, Cylas formicarius elegantulus (Coleoptera; Curculionidae) on four cultivars of sweetpotato in Southern Florida. Florida Entomol. 70:523-526.

JANSSON, R.K. 1991. Biological control of Cylas spp. In: R.K. Jansson and K.V. Raman (eds.). Sweet Potato Management. Oxford and IBH Publishing, New Delhi. Pp 169-201.

KAISSLING. K.E. 1974. Sensory transduction in insect olfactory receptors. In: Biochemistry of Sensory Functions. Ed. L. Jaenicke. Springer, Berlin. pp. 243275.

KLOCHKOV, S.G., and PUSHIN, A.N. 1989a. Trail pheromone of Kalotermes flavicollis. Chem. Nat. Comp. 25:115-118.

KOCHANSKY, J.P., ROELOFS, W.L., and SIVAPALAN, P. 1978. Sex pheromone of the tea tortrix moth (Homona coffearia Neitner). J. Chem. Ecol. 4:623-631.

LÖFSTEDT, C., LÖFQVIST, J., LANNE, B.S., VAN DER PERS, J.N.C., and HANSSON, B.S. 1986. Pheromone dialects in European turnip moths Agrotis segetum. Oikos. 46:250-257.

MAO, L., STORY, R.N., HAMMOND, A.M., and LABORTE, D.R.. 2001. Effect of sweetpotato genotypes, storage time and production site on feeding and oviposition behavior of the behavior of the sweetpotato weevil, Cylas formicarius (Coleoptera, Apionidae). Florid. Entomol. 84:259-264

MCDONOUGH, L.M., AVERILL, A.L., DAVIS, H.G., SMITHHISLER, C.L., MURRAY, D.A., CHAPMAN, P.S., VOERMAN, S., DAPSIS, L.J., and AVERILL, M.M. 1994. Sex pheromone of cranberry fruitworm, Acrobasis vaccinii Riley (Lepidoptera: Pyralidae). J. Chem. Ecol. 20:3269-3279.

MEIJERINK, J., BRAKS, M.A.H., BRACK, A.A., ADAM, W., DEKKER, T., POSTHUMUS, M.A., VAN BEEK, T.A., and VAN LOON, J.J.A. 2000. Identification of olfactory stimulants for Anopheles gambiae from human sweat samples. J. Chem. Ecol. 26:1367-1382.

NEISES, B. And Steglich. W. 1978. Simple methods for the esterification of carboxylic acids. Angew. Chem. Int. Ed. 17:22-524.

PEPPUY, A., ROBERT, A., SEMON, E., GINIES, C., LETTERE, M., BONNARD, O., and BORDEREAU, C. 2001a. (Z)-dodec-3-en-1-ol, a novel termite trail pheromone identified after solid phase microextraction from Macrotermes annandalei. J. Insect Physiol. 47:445-453.

PEPPUY, A., ROBERT, A., SEMON, E., BONNARD, O., SON, N.T., and BORDEREAU, C. 2001b. Species specificity of trail pheromones of fungusgrowing termites from northern Vietnam. Insectes Soc. 48:245-250.

ROELOF, W.L. 1978. Threshold hypothesis for pheromone perception. J. Chem. Ecol. 4:685-699.

ROELOFS, W.L., and BROWN, R.L. 1982. Pheromones and evolutionary relationships of Tortricidae. Ann. Rev. Ecol. Syst. 13:395-422. 
SATO, K., URITANI, L. and SAITO, T. 1981. Characterization of the terpene-inducing factor isolated from the larvae of the sweetpotato weevil Cylas formicarius Fabricius (Coleoptera:Brentidae). Appl. Entomol. Zool. 16:103-112.

SCHULZ, S. 1997. The chemistry of spider toxins and spider silk. Angew. Chem. Int. Ed. 36:314-326.

SILVERSTEIN, R.M. 1981. Pheromones: Background and potential use in insect pest control. Science 213: 1326-1332.

SILVERSTEIN, R.M. and YOUNG, J.C. 1976. Insects generally use multi-component pheromone. In: M. Beroza (ed.)Pest Management With Sex Attractants and Other Behavior-Controlling Chemicals. American Chemical Society Symposium Series 23, Washington, D.C. pp. 1-29.

SMIT, N.E.J.M., MAGENYA, O., and PARKER, B.L. 1994. Biology and pheromone studies with the sweetpotao weevils, Cylas puncticollis and C. brunneus. In: F. Ofori and S.K. Hahn (eds.). Tropical root Crops in Developing Economy. Proceedings of the $9^{\text {th }}$ Conference of the International Socity for Tropical Root Crops, October 20-26, 1991, Accra, Ghana, IITA, Ibadan, Nigeria. pp. 399-405.

STAEDLER, E. 1972. Ueber die Orientierung un das Wirtswahlverhalten der Möhrenfliege, Psila rosae (Diptera: Psilidae). II. Imagines. Z. Angew. Entomol. 70: $29-61$.

STAEDLER, E. 1974. Host plant stimuli affecting oviposition behavior of the eastern spruce budworm. Entomol. Exp. Appl. 17:176-88.

STRUBLE, D.L., BYERS, J.R., MCLEOD, D.G.R., and AYRE, G.L. 1987. Sex pheromone components of an Alberta population of European corn borer, Ostrinia nubilalis (Hbn.) (Lepidoptera: Pyralidae). Can. Entomol. 119:291-299.

SVENSSON, B.G., and BERGSTRÖM, G. 1979. Marking pheromones of Alpino bombus males. J. Chem. Ecol. 5:603-615.

TALEKAR, N.S. 1988. Insect pests of sweetpotato in the tropics. In: Proceedings of the 11 International Congress of Plant Protection, Manila. Philippines.

TALEKAR, N.S. and LEE, S.T. 1989. Studies on the utilization of a female sex pheromone for the management of sweet potato weevil, Cylas formicarius formicarius (Coleoptera: Curculionidae). Bull. Inst. Zool. Acd. Sinn. 28:281-288.

URITANI, I., SAITO, H., HONDA, H., and KIM, W.K. 1975. Induction of furanoterpenoids in sweet potato roots by larval components of the sweet potato weevils. Agric. Biol. Chem. 39: 1857- 1862.

VANG, L.V., INOMATA,S.-I., KINJO, M., KOMAI, F., and ANDO, T. 2005. Sex pheromones of five olethreutine species (Lepidoptera: Tortricidae) associated with the seedlings and fruits of mangrove plants in the Ryukyu islands, Japan: identification and field evaluation. J. Chem. Ecol. 31:859-878.

VILLACARLOS, L.T., VASQUEZ, E.A. and MANDRAS, B. T. 1995. Field Evaluation of Pheromone and Metarrhizium anisopliae for the control of sweetpotato weevil Cylas formicarius (F.). In: The Potato and Sweetpotato in Southeast Asia and the Pacific Region - Research Results Presented in a Series of Working Papers 19931995. International Potato Center. p. 178-186.

VISSER, J.H. 1986. Host odor perception in phytophagous insects. Annu. Rev, Entomol. 31:121-144.

WHITTLE, C.P., BELlAS, T.E., HORAK, M., and PINESE, B. 1987. The sex pheromone and taxonomic status of Homona spargotis Meyrick sp. rev., an Australian pest species of the Coffearia group (Lepidoptera: Tortricidae: Tortricinae). J. Aust. Entomol. Soc. 26:169-179. 
WITZGAlL, P., BENGTSSON, M., RAUSCHER, S., LIBLIKAS, I., BACKMAN, A.C., CORACINI, M., ANDERSON, P., and LÖFQVIST, J. 2001. Identification of further sex pheromone synergists in the codling moth, Cydia pomonella. Entomol. Exp. Appl. 101:131-141. 